\title{
Computational analysis of the electromechanical consequences of short QT syndrome
}

\author{
Christopher L.-H. Huang* \\ Physiological Laboratory, University of Cambridge, UK \\ *Correspondence: clh11@cam.ac.uk \\ Edited by: \\ Mark Potse, Inria Bordeaux Sud-Ouest, France \\ Reviewed by: \\ Viatcheslav Gurev, International Business Machines, USA \\ Frits W. Prinzen, Maastricht University, Netherlands
}

Keywords: short QT syndrome, cardiac arrhythmia, sudden cardiac death, potassium channels, computational analysis, electromechanical coupling

\section{A commentary on}

In silico investigation of the short QT syndrome, using human ventricle models incorporating electromechanical coupling by Adeniran, I., Hancox, J. and Zhang H. (2013). Front. Physiol. 4:166. doi: 10.3389/fphys.2013.00166

Exceptional scientific work inquires into new areas or utilizes techniques circumventing existing limitations to study. Alternatively, it may provide insights extending or complementing existing understanding, or generate hypotheses amenable to or worthy of further testing. Adeniran et al. (2013) complete a sequence of physiological papers fulfilling several of these criteria. These address the familial, relatively recently described, cardiac arrhythmic disease of short QT syndrome (SQTS) (Gussak et al., 2000). SQTSs are electrocardiographically characterized by shortened QT intervals $(\sim 320 \mathrm{~ms})$ and peaked T-waves despite normal cardiac anatomy (Patel and Pavri, 2009). They are clinically associated with syncope, shortened atrial and ventricular effective refractory periods and increased atrial and, potentially fatal, ventricular, arrhythmia (Giustetto et al., 2006). They complement the commoner long QT syndromes in terms of arrhythmic mechanisms. Both likely, albeit differently, involve altered refractoriness and tissue vulnerability producing re-entrant, arrhythmic, substrate.

Adeniran et al. (2013) complete a series of papers on SQTS1 (Adeniran et al., 2011) and SQTS3 models (Adeniran et al.,
2012) resulting from genetic alterations in $\mathrm{KCNH} 2$ and $\mathrm{KCNJ} 2$ and therefore in repolarizing $\mathrm{I}_{\mathrm{Kr}}$ (Sun et al., 2011) and $\mathrm{I}_{\mathrm{K} 1}$ ionic currents (Deo et al., 2013) respectively. Classical physiological analysis demonstrated that $\mathrm{K}^{+}$channel openers increase transmural repolarization dispersion and shorten ventricular effective refractory period potentially producing arrhythmogenic substrate in left ventricular wedge preparations (Patel and Antzelevitch, 2008). It is important to bear in mind that although useful tools in gaining physiological insights, pharmacological agents can show non-specificities in their actions. However, analyses using genotypically accurate animal SQTS models avoiding such manipulations are lacking. Adeniran et al. (2011, 2012) had introduced a first paradigm shift complementing relatively sparse available experimental data through computational explorations of the electrophysiological basis for arrhythmia in SQTS. They used Markov and/or Hodgkin-Huxley formulations developed from experimental data obtained from expression systems modeling N588K$h E R G$ and D172N-Kir2.1 mutations to replicate SQT1 and SQT3. This demonstrated increased tissue vulnerability to premature stimuli and increased tendencies to form and maintain reentrant excitation waves in both idealized two-dimensional and more realistic threedimensional tissue (Adeniran et al., 2012).

Adeniran et al. (2013) assessed for potential effects of action potential shortening in SQTS upon human ventricular mechanical dynamics. They explored whether mechano-electric feedback involving stretch-activated channels (Taggart, 1996; Hu and Sachs, 1997; Calaghan et al., 2003) could conversely contribute to dissociation between ventricular repolarization and the end of mechanical systole. This would match clinical observations (Schimpf et al., 2008). Stretch-activated channels have been previously implicated in regulation of electrical activity by altered contractility or volume load (Franz, 1996; Lab, 1996). Previous studies modeling arrhythmogenesis in SQTS had not extended to considering mechanical properties. This entailed ambitious computational compilation of physiological, anatomical and biophysical data into a cells-to-systems reconstruction of cardiac electrophysiological activation, contraction and relaxation.

At the cellular level, an established electrophysiological single cell model recapitulated human ventricular myocyte electrical and membrane channel properties as well as transmural action potential timecourse heterogeneities across the ventricular wall (Ten Tusscher et al., 2004; Ten Tusscher and Panfilov, 2006). This yielded cytosolic $\left[\mathrm{Ca}^{2+}\right]$, sarcoplasmic reticular (SR) and cytoplasmic volumes, SR-Ca ${ }^{2+}$ leak and pump currents, $\mathrm{Ca}^{2+}$ current from dyadic to bulk cytoplasmic space, and background, plateau and $\mathrm{Na}^{+} / \mathrm{Ca}^{2+}$ exchange membrane $\mathrm{Ca}^{2+}$ current. The resulting $\mathrm{Ca}^{2+}$-troponin binding coupled this to a myofilament mechanics model chosen for its realistic basis in the crossbridge cycling model of cardiac muscle contraction (Rice et al., 2008). This latter model has replicated a wide range of experimental data including steady-state 
force-sarcomere length, force- $\mathrm{Ca}^{2+}$ and sarcomere length- $\mathrm{Ca}^{2+}$ relations. The simulations compared results from inclusion or exclusion of stretch-activated current, $I_{\mathrm{SAC}}$.

These cellular level findings were built into predictions for mechanical activity in two and three-dimensional human ventricular tissue models. The modeling of cardiac tissue mechanics permitted a non-linear elasticity (Marsden and Hughes, 1994; Holzapfel, 2000) within an inhomogeneous, anisotropic, incompressible non-linear material (Niederer and Smith, 2008; Pathmanathan and Whiteley, 2009). Including appropriate stress tensors permitted representation of active tension driving longitudinal shortening, wall thickening and rotational twisting of the ventricular wall (Cheng et al., 2008; Coppola and Omens, 2008; Lilli et al., 2013). The geometrical changes were incorporated into the electrophysiological computations (Pathmanathan and Whiteley, 2009). The three-dimensional simulations of human ventricular geometry employed anisotropic fiber orientation data to a $0.2 \mathrm{~mm}$ spatial resolution obtained from diffusion-tensor magnetic resonance imaging. This distinguished endocardial, M-cell and epicardial regions.

The action potential shortening associated with SQT did appear to reduce ventricular mechanical function. Furthermore, this was rectified by an inclusion of stretch-activated channels. This prediction justifies future experimental testing as to whether such channels indeed exert functional effects on cardiac electro-mechanical coupling in SQTS1 and SQTS3. The experimental testing might then explore involvements of $I_{\mathrm{SAC}}$ in normal as well as SQT hearts. In addition, at the theoretical level, the present modeling inevitably entails assumptions of particular implicit physical mechanisms operating within the reconstructions of physiological behavior. It did yield predictions matching previous experimental force-frequency data over frequencies including that at which the simulations were conducted. As outlined in the limitations section of the article, further validation including improved and more physiologically detailed representations of $\mathrm{Ca}^{2+}$ dynamics (Iribe et al., 2006; Grandi et al., 2010; O'Hara et al., 2011) as further experimental data becomes available, will help test uniqueness in the model's predictions. Finally, future predictions of mechanical events might fully encompass ventricular pressure, $P$, its derivative, $\mathrm{d} P / \mathrm{d} t$, as well as the timecourse and amplitude of chamber contraction and relaxation.

Nevertheless, the approach adopted by the authors draws attention to the potential value for modeling that integrates cellular electrophysiological, $\mathrm{Ca}^{2+}$ homeostatic and biomechanical changes with realistic descriptions of cardiac anatomy and mechanical properties. At the broader level we look forward to applications and developments of such approaches at the whole organ level in the analysis of other ion channel exemplars of abnormal cardiac physiology hitherto mainly studied at the cellular or tissue levels. These might include models for the long QT, Brugada and catecholaminergic polymorphic ventricular tachycardia, syndromes (Thomas et al., 2008; Martin et al., 2011; Zhang et al., 2013).

\section{ACKNOWLEDGMENTS}

The author thanks the Medical Research Council and Wellcome Trust, UK and the MacVeigh Benefaction for kind support.

\section{REFERENCES}

Adeniran, I., El Harchi, A., Hancox, J. C., and Zhang, H. (2012). Proarrhythmia in KCNJ2-linked short QT syndrome - insights from modelling. Cardiovasc. Res. 94, 66-76. doi: 10.1093/cvr/cvs082

Adeniran, I., Hancox, J. C., and Zhang, H. (2013). In silico investigation of the short QT syndrome, using human ventricle models incorporating electromechanical coupling. Front. Physiol. 4:166. doi: 10.3389/fphys.2013.00166

Adeniran, I., McPate, M. J. W.,Witchel, H. J., Hancox, J. C., and Zhang, H. (2011). Increased vulnerability of human ventricle to re-entrant excitation in hERG-linked variant 1 short QT syndrome. PLoS Comput. Biol. 7:e1002313. doi: 10.1371/journal.pcbi. 1002313

Calaghan, S. C., Belus, A., and White, E. (2003). Do stretch-induced changes in intracellular calcium modify the electrical activity of cardiac muscle. Prog. Biophys. Mol. Biol. 82, 81-95. doi: 10.1016/S0079-6107(03)00007-5

Cheng, A., Nguyen, T. C.,Malinowski, M., Daughters, G. T., Miller, D. C., and Ingels, N. B. Jr. (2008). Heterogeneity of left ventricular wall thickening mechanisms. Circulation 118, 713-721. doi: 10.1161/CIRCULATIONAHA.107.744623

Coppola, B. A., and Omens, J. H. (2008). Role of tissue structure on ventricular wall mechanics. Mol. Cell. Biomech. 5, 183-196.

Deo, M., Ruan, Y., Pandit, S. V., Shah, K., Berenfeld, O., Blaufox, A., et al. (2013). KCNJ2 mutation in short QT syndrome3 results in atrial fibrillation and ventricular proarrhythmia. Proc Natl. Acad. Sci. U.S.A. 110, 4291-4296. doi: 10.1073/pnas.1218154110

Franz, M. R. (1996). Mechano-electrical feedback in ventricular myocardium. Cardiovasc. Res. 32, 15-24.

Giustetto, C., DiMonte, F., Wolpert, C., Borggrefe, M., Schimpf, R., Sbragia, P., et al. (2006). Short QT syndrome: clinical findings and diagnostictherapeutic implications. Eur. Heart J. 27, 2440-2447. doi: 10.1093/eurheartj/ehl185

Grandi, E.,Pasqualini, F. S., and Bers, D. M. (2010). A novel computational model of the human ventricular action potential and $\mathrm{Ca}$ transient. J. Mol. Cell. Cardiol. 48, 112-121. doi: 10.1016/j.yjmcc.2009.09.019

Gussak, I., Brugada, P., Brugada, J., Wright, R. S., Kopecky, S. L., Chaitman, B. R., et al. (2000). Idiopathic short QT interval: a new clinical syndrome. Cardiology 94, 99-102. doi: $10.1159 / 000047299$

Holzapfel, G. A. (2000). Nonlinear Solid Mechanics: A Continuum Approach for Engineering, 1st Edn. Chichester: Wiley.

Hu, H., and Sachs, F. (1997). Stretch-activated ion channels in the heart. J. Mol. Cell. Cardiol. 29, 1511-1523. doi: 10.1006/jmcc.1997.0392

Iribe, G., Kohl, P., and Noble, D. (2006). Modulatory effect of calmodulin-dependent kinase II (CaMKII) on sarcoplasmic reticulum $\mathrm{Ca}^{2+}$ handling and interval-force relations: a modelling study. Philos. Trans. A Math. Phys. Eng. Sci. 364, 1107-1133. doi: 10.1098/rsta. 2006.1758

Lab, M. J. (1996). Mechanoelectric feedback (transduction) in heart: concepts and implications. Cardiovasc. Res. 32, 3-14.

Lilli, A., Baratto, M. T., Meglio, J. D., Chioccioli, M., Magnacca, M., Talini, E., et al. (2013). Left ventricular rotation and twist assessed by fourdimensional speckle tracking echocardiography in healthy subjects and pathological remodeling: a single center experience. Echocardiography 30, 171-179. doi: 10.1111/echo. 12026

Marsden, J. E., and Hughes, T. J. R. (1994). Mathematical Foundations of Elasticity. Englewood Cliffs, NJ: Dover Publications and Prentice-Hall.

Martin, C. A., Guzadhur, L., Grace, A. A., Lei, M., and Huang, C. L.-H. (2011). Mapping of reentrant spontaneous polymorphic ventricular tachycardia in a Scn5a+/- mouse model. Am. J. Physiol. Heart Circ. Physiol. 300, H1853-1862. doi: 10.1152/ajpheart.00034.2011

Niederer, S. A., and Smith, N. P. (2008). An improved numerical method for strong coupling of excitation and contraction models in the heart. Prog. Biophys. Mol. Biol. 96, 90-111. doi: 10.1016/j.pbiomolbio.2007.08.001

O’Hara, T., Virág, L., Varró, A., and Rudy, Y. (2011). Simulation of the undiseased human cardiac ventricular action potential: model formulation and experimental validation. PLoS Comput. Biol. 7:e1002061. doi: 10.1371/journal.pcbi.100206

Patel, C., and Antzelevitch, C. (2008). Cellular basis for arrhythmogenesis in an experimental model of the SQT1 form of the short QTsyndrome. Heart Rhythm 5, 585-590. doi: 10.1016/j.hrthm.2008.01.022 
Patel, U., and Pavri, B. B. (2009). Short QT syndrome: a review. Cardiol. Rev. 17, 300-303. doi: 10.1097/CRD.0b013e3181c07592

Pathmanathan, P., and Whiteley, J. P. (2009). A numerical method for cardiac mechano electric simulations. Ann. Biomed. Eng. 37, 860-873. doi: 10.1007/s10439-009-9663-8

Rice, J. J., Wang, F., Bers, D. M., and de Tombe, P. P. (2008). Approximate model of cooperative activation and crossbridge cycling in cardiac muscle using ordinary differential equations. Biophys. J. 95, 2368-2390. doi: 10.1529/biophysj.107.119487

Schimpf, R., Antzelevitch, C., Haghi, D.,Giustetto, C., Pizzuti, A., Gaita, F., et al. (2008). Electromechanical coupling in patients with the short QT syndrome: further insights into the mechanoelectrical hypothesis of the $\mathrm{U}$ wave. Heart Rhythm 5, 241-245. doi: 10.1016/j.hrthm.2007.10.015

Sun, Y., Quan, X.-Q., Fromme, S., Cox, R. H., Zhang, P., Zhang, L., et al. (2011). A novel mutation in the KCNH2 gene associated with short QT syndrome. J. Mol. Cell. Cardiol. 50, 433-441. doi: 10.1016/j.yjmcc.2010.11.017
Taggart, P. (1996). Mechano-electric feedback in the human heart. Cardiovasc. Res. 32, 38-43.

Ten Tusscher, K. H. W. J., Noble, D., Noble, P. J., and Panfilov, A. V. (2004). A model for human ventricular tissue. Am. J. Physiol. Heart Circ. Physiol. 286, H1573-H1589. doi: 10.1152/ajpheart.00794.2003

Ten Tusscher, K. H. W. J., and Panfilov, A. V. (2006). Alternans and spiral break up in a human ventricular tissue model. Am. J. Physiol. Heart Circ. Physiol. 291, H1088-H1100. doi: 10.1152/ajpheart.00109.2006

Thomas, G., Killeen, M. J., Grace, A. A., and Huang, C. L.-H. (2008). Pharmacological separation of early afterdepolarizations from arrhythmogenic substrate in $\triangle \mathrm{KPQ} S c n 5 a$ murine hearts modelling human long QT 3 syndrome. Acta Physiol. 192, 505-517. doi: 10.1111/j.1748-1716.2007. 01770.x

Zhang, Y., Wu, J., Jeevaratnam, K., King, J., Guzadhur, L., Ren, X., et al. (2013). Conduction slowing contributes to spontaneous ventricular arrhythmias in intrinsically active murine $R y R 2-P 2328 S$ hearts. J. Cardiovasc. Electrophysiol. 24, 210-218. doi: $10.1111 /$ jce. 12015
Conflict of Interest Statement: The author declares that the research was conducted in the absence of any commercial or financial relationships that could be construed as a potential conflict of interest.

Received: 11 October 2014; accepted: 29 January 2015; published online: 11 February 2015.

Citation: Huang CL-H (2015) Computational anal$y$ sis of the electromechanical consequences of short QT syndrome. Front. Physiol. 6:44. doi: 10.3389/fphys. 2015.00044

This article was submitted to the journal Frontiers in Physiology.

Copyright (C) 2015 Huang. This is an open-access article distributed under the terms of the Creative Commons Attribution License (CC BY). The use, distribution or reproduction in other forums is permitted, provided the original author(s) or licensor are credited and that the original publication in this journal is cited, in accordance with accepted academic practice. No use, distribution or reproduction is permitted which does not comply with these terms. 